\title{
La crisis del movimiento socialdemócrata en América Latina
}

\begin{abstract}
SUSANNE BODENIIEIMER, cientista politica, es miembro del Centro de estudios latinoanericanos de la Universidad de California, Berkeley. Es autora de varios trabajos sobre movimientos politicos y laborales en América Latina y ha integrado diversos equipos docentes norteamericanos de investigación sobre América Latina.
\end{abstract}

Hace apenas nueve años, 1960 , que el movimiento socialdemócrata en América Latina pareció haber cobrado una nueva vida. La elección de John F. Kennedy y el "new look" de su politica para América Latina despertó grandes esperanzas entre los socialdemócratas de los paises latinoamericanos. Asi parecia que la temida revolución violenta no seria necesaria después de todo. Con la ayuda y apoyo de la administración liberal de Washington, los gobiernos demócratas de América Latina podrian recorrer el camino no-comunista, gradual y pacíico, para finalmente alcanzar las reformas y el progreso económico en sus respectivos paîses.

Hoy en dia, casi 10 años más tarde, han disminuido mucho esas esperanzas. La brecha económica entre América Latina y las naciones industrialmente avanzadas es cada vez más grande; muy pocas reformas, si en efecto ha habido algunas, en el campo del agro, del sistema tributario, del sistema bancario, etc., han sido llevadas a cabo bajo la Alianza para el Progreso; dictaduras militares han reemplazado a regimenes civiles "democráticos" en muchos de los paises. Estos acontecimientos indican no sólo la naturaleza ilusoria de la visión socialdemócrata del cambio profundo, al tiempo que gradual y pacífico, en América Latina, sino también el fracaso de los socialdemócratas mismos en su intento de hacer realidad dicha visión. La crisis profunda de la Socialdemocracia en América Latina no es imputable en sus causas al asesino del 22 de noviembre de ${ }^{663}$, muerte de John F. Kennedy, ni tampoco a ningún suceso externo. Para explicarnos esa crisis debemos, más bien, considerar a los socialdemócratas mismos; debemos reexaminar su ideologia, la base de clases 


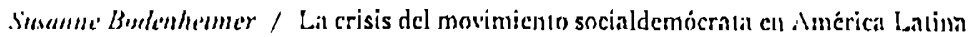
sobre la que sc sustenta, y cstudiar todo ello desde una nueva perspectiva, yendo más allá de las interpretaciones, con frecuencia superficiales, dadas por ellos y sus partidarios en los Estados Unidos'. A pesar de que una profunda comprensión del papel que ellos juegan en América Latina requeriria un estudio detallado y/o comparativo, nuestra intención en este trabajo es hacer una semblanza general del movimiento sociaiúemócrata internacional en América Latina y de la actuación de los movimientos socialdemócratas en algunos de los páises del continentc.

La internacional socialdemócrata en Amćrica Latina concretamente cstá ligada por una serie de organizaciones hemisféricas $y$ subjetivamente, por una ideologia siempre presente $y$ un sentido de solidaridad en el propósito común. Incluidos en este movimiento internacional se encuentran: el Partido Liberación Nacional (PLi) de Costa Rica, Acción Democrática (AD) de Venezuela, Alianza Popular Revolucionaria Americana (APRA) del Perú, Partido Revolucionario Dominicano (YRD) de la República Dominicana, el Partido Popular Democrático (PPD) de Puerto Rico, Partido Revolucionario de Guaremala, Partido Liberal de Honduras, Partido Liberal Independiente de Nicaragua, Partido Febrerista del Paraguay, Partido Radical (PR) de Chile, Partido Colorado del Uruguay, Movimiento Nacionalista Revolucionario (MR) de Bolivia, algunas agrupaciones cubanas en exilio y quizás cl Partido Revolucionario Institucional (PRI) de México. Claro está que existen diferencias significativas entre estos partidos tanto en su origen histórico como en su desarrolio, $y$ por consecuencia en la ideologia que los anima. Algunos de ellos, como el APRA en el Perú, tienen sus comienzos en los años 20, mientras que otros, entraron en escena más recientemente. Algunos han tenido éxito en la toma del poder gubernamental, como por ejemplo, AD en Venczucla, cl PRr en México, el Partido Radical en Chile y el 'is en Costa Rica, otros han gobernado por cortos espacios de tiempo para luego ser derrotados por golpes militares, como el PRD en la República Dominicana, el Partido Liberal en Honduras, el MNR en Bolivia, $y$ en fin otros que nunca

: Comio ejemplo de la interprelación socialdemócrala tipica, ver Harry Kantor, "Los Particlos Populares de América Latina", Journal of Inter-fimerican Sludies, abril, 196 Roberi Alexander, Latin American Politics and Covermment (New York: Harper and Row, 1g(j). Capitulo $8_{i}$ R. Alexander, "The Latin American Aprista Parties", Political Quarter(j), julio-septiembre, 1949. pp. 236-17; Armando Villanueva, "Paritidos Demócrnta-Revoiucionarios en Indoamérica", Combale, $\mathrm{N}^{\circ} \mathrm{s} .18,19$ y 20. 
han llegado al gobierno, como ser el Partido Liberal Independiente de Nicaragua, el ApkA en el Perú. Algunos de ellos, tales como el Apka, tuvieron, en sus inicios, la infuencia del pensamiento marxista, mientras que otros, tales como el PLN, no la tuvicron. En paises como el Perú y México, la corriente socialdemócrata fue conformada por lä invocación hecha a la tradición cultural indigena (india), la que no existe en otros paises tales como Costa Rica, Chile y'Uruguay. Finalmente, como lo hemos de ver más adelante, como resultado de sus variadas experiencias dentro de los respectivos paises, unos cuantos de ellos, especialmente el PRD en la República Dominicana, quien sintió el impacto del poderio norteamericano en su invasión de 1965 , se han radicalizado, mientras que otros han intentado mantener, más o menos, la misma posición, como por ejemplo el PLN Y AD, o han pasado a formar parte de la Derecha como el APRA. Incluso tomando en cuenta las variaciones importantes que existen entre ellos, sin embargo, estos partidos diversos tienen mucho en común para ser considerados - como se consideran ellos mismos- como una unidad.

La particularidad común de estos partidos (referidos unas veces como "socialdemócratas", otras como "populares", "social-revolucionarios", en fin "apristas", y considerándose a si mismos como la "izquierda democrática" de América Latina) es la ideologia, cuýos principios básicos pueden ser sintetizados de la siguiente forma: 1) una dedicación, casi obsesiva, a la mantención de instituciones formales de la democracia: vgr. sistcma electoral, control parlamentario sobre el poder del ejecutivo, ctc., y uná correspondiente aversión hacia lo que ellos consideran dictaduras de derecha, como por ejemplo las dictaduras militares o sus equivalentes en Nicaragua, Haiti, Paraguay', etc., o de izquierda: Cuba; 2) oposición a la oligarquía "feudal" (especialmente la "aristocracia terrateniente") que ha privado a las clases media y baja de su acceso al poder politico, económico y social; 3) propician una economia nacional programada $y$ una cierta regulación de la economia pero sin abolir la institución de la propicdad privada; 4) llevar a efecto medidas en pro del bienestar social en los campos de la educación, vivienda, salud, seguridad social y otras áreas sujetas a reformas y una insistencia, débil en la práctica, no asi en la tcoría, en las llamadas rcformas estructurales, como la reforma tributaria, bancaria, etc. El énfasis está en las reformas que eleven las condiciones de vida de las masas sin que ellas signifiquen una amenaza scria 
Susanne Bodenheimer / La crisis de! movimicnto socialdemócrata en América Latina a los intereses particulares tanto nacionales como extranjeros; 5) el anticomunismo es un principio generalizado que ha llevado a algunos de los partidos - tales como el PLN, PR y $A D$ - cuando se encontraban en el poder, a poner fuera de la ley a los partidos y movimientos comunistas $y$, como corolario natural, un odio intenso hacia la Cuba de Castro; sentimiento éste originado en el convencimiento que tienen de haber sido "traicionados", particularmente en aquellos que en 1959 habian defendido la revolución cubana, pensando que Castro estableceria en Cuba una variante del modelo socialdemócrata"; 6) aceptación general de la "necesidad" de capital extranjero como estimulo al desarrollo, posición ésta matizada, a veces, por quejas acerca de la intervención y los métodos crudos empleados por los consorcios extranjeros en su interferencia en los asuntos nacionales; de ahi que los socialdemócratas se oponen al estilo y no al contenido del imperialismo; 7) un fuerte sentimiento de identificación como parte del mundo occidental ("libre") y en general una actitud pronorteamericana, particularmente en la época del gobierno Kennedy' y la Alianza para el Progreso, como fue concebida originalmente. Actitud temperada por cierto criticismo de los Estados Unidos por su insensibilidad hacia el desarrollo y problemas del intercambio de América Latina; por su defensa incondicional de las empresas extranjeras que operan en el continente, y por su abierta colaboración con las dictaduras militares; siendo todo esto considerado, sin embargo, como "errores" de la política norteamericana y no como consecuencia necesaria e intrínseca del sistema socioeconómico de los Estados Unidos.

Independientemente de esta serie de principios generalmente aceptados, los partidos socialdemócratas están, asimismo, arraigados sobre bases más o menos similares. Un socialdemócrata norteamericano ha hecho notar que estos "partidos se desarrollan durante el siglo $\mathrm{xx}$ como instrumentos de una nueva clase media y de la clase trabajadora con el objetivo de reorganizar la sociedad semifeudal que prevalecia en América Latina

'2 Por ejemplo el mensaje de Norman Thomas en Latinoamérica más allá de sus fronteras (San José, Costa Rica: Ediciones Combate, 1960), p. 18; Sacha Volman, "El General Batista y la revolución comunista", Combate, $\mathrm{N}^{\circ}$ I; Luis Alberto Monge, "No hay revolu.ción sin libertad", separata de Combate, $N^{0}: 4$; concerniente a la primera actitud de Figucres frente a la revolución cubana, ver Hispanic-American Report (Stanford), marzo 1959 y abril : 959 . 
ESTU I I OS I N TER N A C : O N A L E S

a comienzos de siglo". Dichos partidos "representan", sostiene él, a los obreros (particularmente a la clase obrera organizada), a la nueva clase media, los campesinos, los indios, negros, mestizos, y a aquellos "pocos individuos de fortuna, quienes comprenden que la industrialización es imposible sin la ampliación de los mercados nacionales"; sus enemigos son los latifundistas y los comerciantes ricos, los grupos católicos tradicionales, los campesinos conservadores y todos aquellos que tienen una excesiva admiración por una forma de vida no-latinoamericana: francófilos o comunistas prosoviéticos ${ }^{4}$. Estos partidos, de acuerdo a su propia convicción, están basados en una alianza de todas las fuerzas reformistas y progresistas $y$ por ende en una alianza de diferentes clases sociales. Como dice un personero del APRA: "Rechazando la mentalidad servil y colonialista de los comunistas, cuya consigna era la de que el proletariado ега la única clase revolucionaria, Haya de la Torre ha dicho que el heroico papel jugado por el campesinado en su función de proletariado, asi como la clase media de los paises atrasados, donde el pequeño capitalista, el pequeño industrial, el pequeño agricultor, el pequeño propietario urbano, el pequeño minero, el pequeño comerciante, el intelectual, el empleado, etc., son víctimas de la opresión imperialista y oligárquica, siendo por consiguiente todos ellos fuerzas incorporadas dentro del marco de la lucha revolucionaria"s. Este énfasis puesto en la necesidad de un frente popular de campesinos, obreros y miembros de la clase media (incluidos los industriales) ${ }^{6}$ nace del análisis del desarrollo latinoamericano como un proceso eliminatorio de la denominación ejercida por los intereses oligárquicos "feudales", para asi despejar el camino para la democracia politica y la industrialización. Sin duda alguna hubo un periodo en el cual dicho análisis tenia cierta relación con la realidad socioeconómica de América Latina; a comienzos de este siglo estos movimientos lucharon contra las oligarquias terrateniente y comercial pero no "feudal" y sus correspondientes sistemas de dictaduras. De ahi pues que la mayoria de los partidos socialdemócratas se fueron configurando a partir de movimientos de oposición. Hoy en dia, sin embargo, esta etapa ha sido superada y el

3 Kantor, "Los Partidos Populares...", p. 221.

4 Kantor, op. cit., p. 232; también Alexander, op. cit., p. 62.

5 Villanueva, op. cil, en Combate, $N^{0}: 8, \mathrm{pp} .14-15$, citando a Haya de la Torre; ver tambiér Villanueva, op. cit., en Combate, $\mathrm{N}^{\circ} 20$.

${ }^{6}$ Villanueva en Combate, $N^{\circ} 20$, p. 56 . 
Stsanne Bodenheimer / La crisis del movimiento socialdemócrata en Amćrica Latina proceso de industrialización se halla en marcha en la mayoria de los paises. No es posible pues seguir identificando a la oligarquía como el único y mayor obstáculo para el desarrollo uiterior; y a la inversa, la clase media industrial (la "burguesia nacional") no es más, en la medida de que pudo haber sido, la "vanguardia" del movimiento revolucionario nacional: ha consolidado su posición socioeconómica al tiempo que ha adquirido intereses considerables que tiene que defender. Estos partidos, habiéndose originado y permanecido como vehículos, de la clase media, reflcjan los intereses en proceso de cambio de esta clase. Veamos cómo un estudioso de ellos los distingue de los movimientos más radicales:

"La fisonomia de clase media de estos partidos se define claramente cuando se examinan las medidas politicas y doctrinas que preconizan. Cuando estos partidos aparecieron por primera vez como pretendientes al poder politico, sus enunciados doctrinarios se relacionan, en casi su totalidad, con temas politicos. Se convierten en defensores de gobiernos representativos, de las libertades civiles y de la honestidad administrativa. Estos llamamientos tienen interés particular para los activistas del sector medio, quienes habrán de formar el núcleo central alredecor del cual se ha de edificar un movimiento politico... Incluso las reformas tanto económicas como sociales propuestas por estos partidos reflejan el dominio de este sector medio en la formulación política. Muchos de los intrincados enunciados ideológicos de estos partidos están delineados para demostrar que la elevación del nivel de vida del pueblo como un todo puede ser llevada a efecto en la mejor medida posible a través de activistas que esencialmente pertenecen al sector medio, en otras palabras, es la función de! sector medio. La obtención de créditos para nuevas empresas, la asistencia técnica más avanzada, el desarrollo del comercio y el fomento del turismo, el sentido urbano que con frecuencia se hace presente en los fondos dedicados a la educación, la salud pública, obras viales y otros servicios públicos, todos son programas de interés particular para los sectores medios..."

Por consiguiente, en la medida en que los partidos socialdemócratas continúen manteniendo su base política en una alianza multiclasista se convierten en expresión politica de la hegemonia de las clases medias sobre

7 Charles Anderson, "Central American Political Parties", Western Political Quarterly, mario $19^{62}$, pp. $: 35-6$. 
las clases "aliadas". Es precisamente-por esta razón que, a pesar de que se hayan originado como movimientos "cuasirrevolucionarios", estos partiodos en su ofensiva por un cambio radical han adoptado, en los últimos años, una posición defensiva y por lo tanto no significan una amenaza seria a los viejos intereses creados de terratenientes, comerciantes e industriales, que en muchos aspectos se han convertido en intereses de la burguesia. Cierto, estos partidos hace mucho habrian perdido todo significado como movimientos de masas si no hubiesen conservado en sus filas a miembros de las clases inferiores; con este objetivo continúan propiciando ciertos tipos de reformas, necesarias en toda América Latina. De ahi que la tarea vigente que tienen estos partidos es el equilibrio entre la urgente reforma y una preocupación, cautelosa por cierto, por los interescs económicos y nacionales ya cstablecidos. El éxito al que pudieran llegar depende de la "habilidad que tengan de llevar a efecto suficientes reformas que satisfagan a las masas y el sector medio que los apoyan, y al mismo tiempo no pongan en peligro inminente la posición de las clases altas".

De acuerdo a ello, independientemente de las muchas diferencias que los afecta, los partidos socialdemócratas han ocupado más o menos una posición similar en sus respectivos paises y, teóricamente por lo menos, han auspiciado doctrinas y' programas similares. Es lógico pues que busquen formalizar sus afinidades a través de organizaciones internacionaies. El movimiento internacional cobró un mayor vigor gracias a las amistades personales de muchos de los dirigentes, en particular a la amistad mutua entre José Figueres del PLx', Haya de la Torre del Apra y Rómulo Betancourt de AD, y en menor grado a la de Juan Bosch del PRD y Luis Muñoz Marin del PPD. Los vinculos que unen a los miembros de este "club" demócrata se originan en la década del 40, época en la que muchos de ellos se encontraban en exilio juntos", $y$, a pesar de ciertas fricciones que existen entre ellos ${ }^{10}$, dichos vinculos han seguido uniéndolos en las décadas del 50 y 60.

- Charles Anderson, op. cit., p. $13^{8 .}$

9Kantor, "La colaboración entre los partidos", Panorama, $N^{\circ}$ :2, nov.-dic., 1964, p. 69.

10 Luis Alberto Monge, Secretario General del plx de Costa Rica, entrevistado por Donn Soott Smith. The Partido Liberación . Vacional of Costa Rica; A Critical Study' (tesis no publicada, presentada en la Universidad de Princeton, Woodrow Wilson School, 1966), p. :8. 
Susanne Bodenheimer / La crisis del movimiento socialdemócrata en América Latina

Una de las primeras expresiones de este movimiento internacional fue la Legión del Caribe, brigada militar semiciandestina y semiformal, constituida principalmente por exiliados socialdemócratas de varias naciones caribeñas, que se impuso como tarea derrocar las dictaduras de sus respectivos paises. La Legión fue.fundada en 1947 en Cuba, antes de la era de Batista, y desde alli se lanzó una invasión fracasada a la República Dominicana que en ese entonces se encontraba bajo la dictadura de Trujillo". Más tarde Costa Rica pasó a ser la base de operaciones gracias a la victoria de Figueres en la revolución de 1948 , la cual fue obtenida en gran medidá por la ayuda militar recibida del gobierno guatemalteco de Arévalo y a la participación activa de exiliados de otros paises, miembros de la Legión, en el ejército de Figueres ${ }^{12}$. Después de la victoria, Figueres reorganizó la Legión y continuó subsidiándola y entrenándola en Costa $\mathrm{Rica}^{13}$. La Legión ocupó la atención mundial en diciembre de 1948 , Juego de un intento de invasión contra la Junta Revolucionaria de Figueres, llevada a cabo por sus enemigos politicos costarricenses ayudados, según se dice, por el régimen de Somoza. Cuando Costa Rica recurrió a la OEA para denunciar la "interferencia" nicaragüense en los asuntos internos de Costa Rica, la OEA resolvió, además, que Costa Rica disolviese lo que aún quedaba de la Legión, la que se encontraba dedicada a derrocar las dictaduras de Honduras, República Dominicana, Nicaragua, El Salvador y Venezuela ${ }^{14}$. Figueres ya había anunciado en noviembre de 1948 la disolución de la Legión ${ }^{15}$; sea como fuere, el entrenamiento militar de la Legión fue suspendido en Costa Rica, después de la resolución de la OEA y posteriormente la Legión se trasladó a Guatemala ${ }^{16}$. No obstante

1: Carta del gobierno de la República Dominicana del 15 de agosto de 1949 al Comité interamericano para la paz de la oes, citada por Enrique Corominas, In the Caribbean Political Areas (traducción de L. Charles Foresti) (University Press of Cambridge, :954), pp. $5 \tilde{\text { y y ss. }}$

12 E. Corominas, p. 59; John Martz, Central America (Chapel Hill: University of North Carolina Press, 1959), p. 255; Kantor, "La colaboración...", p. 70; Alberto Bayo, Tempestad en el Caribe, (Níxico, 1950), P. 96.

13 Corominas, op. cit., pp. 59-6r; Bay'o, op. cit., PP. 93, 132.

${ }^{14}$ Martz, op. cil., p. 185; Cornminas, op. cit., p. 83; Hispanic American Report (de aqui en adelante citado como $11 \mathrm{~A}$ ), dic. $194^{8}$.

25 WAR, noviembre, 19.48 .

16 Bisyo, op. cit., p. 150. 
ESTUDIOS INTERNAGIONALES

ello, el régimen de Somoza en los años 1948 y $: 949$ y en repetidas ocasiones hasta 1955 continuó denunciando el encontrarse amenazado por las actividades revolucionarias de la Legión (intentos de asesinato, golpes revolucionarios, etc.) con base en Costa Rica ${ }^{17}$. A pesar dé los desmentidos del gobierno de Figueres, continuóse especulando acerca de la existencia de la Legión. Durante las elecciones de 1953 en Costa Rica, por ejemplo, se rumoreaba que la Legión se encontraba en entrenamiento en Guatemala para intervenir en favor de Figueres en caso de que éste perdiese las elecciones ${ }^{18}$. Inmediatamente después que Figueres se hizo cargo del gobierno en 1954, se descubrió un complot para asesinar a Somoza. Los exiliados nicaragüenses que habian sido entrenados en Costa Rica, en una hacienda de Figueres, de acuerdo a una versión de los acontecimientos, se hallaban implicados en el complot y que altos personeros del gobierno de Figueres conocian los planes del asesinato de Somoza ${ }^{19}$. En junio de 1955, Figueres nuevamente se vio obligado a negar que él fuese el dirigente de un grupo revolucionario de politicos latinoamericanos ${ }^{20}$, después de que Ulate, ex Presidente de Costa Rica, acusó, en una denuncia escrita, a Figueres de continuar dando ayuda a movimientos revoluciónarios y de haber colaborado con los gobiernos de Arévalo y Arbenz de Guatemala ${ }^{21}$. Incluso en 1959 se dijo que un cierto número de cubanos se encontraba en entrenamiento, en las montañas costarricenses, para formar parte de la Legión ${ }^{22}$. Es cierto que las actividades de la Legión siempre estuvieron envueltas en el misterio y por lo tanto es dificil saber cuán activa se encontraba y hasta qué punto Figueres se hallaba envuelto en ella después de 1949. Todos los intentos de sus simpatizantes socialdemócratas de negar la existencia de la Legión ${ }^{23}$ no dieron resultado positivo; veamos lo que dice al respecto el Presidente del Consejo de la OEA, organización qué habia investigado el caso:

"Puede afirmarse que la Legión del Caribe no fue simple invención de aquellos que defienden los llamados gobiernos fuertes del Caribe, pero

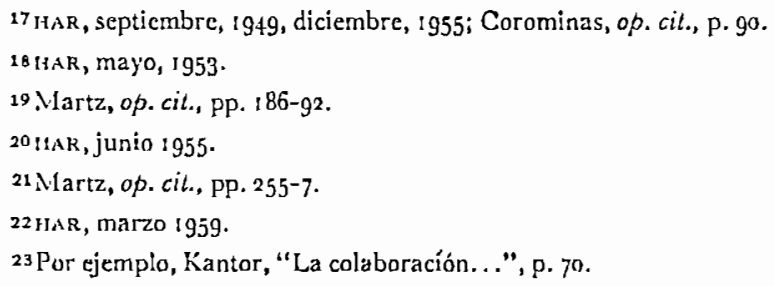


Susanne Bodenheimer / La crisis del movimiento socialdemocrata en America Latina que en efecto es un movimiento que existe, y que es fácil\comprobar su existencia, que sobre la base de un derecho adjudicado a si misma de defensa propia, de acción democrática definida de acuerdo a conceptos propios de sus miembros, ha creado una amenaza concreta contra muchas repúblicas..."24. Quizás la experiencia de la Legión sirvió como precedente a los grupos de cubanos anticastristas en su entrenamiento en varios países centroamericanos para la "liberación" de Cuba.

Otra organización internacional intimamente relacionada con los partidos socialdemócratas de América Latina hà sido la Organización Regional Laboral Interamericana (ORIT), el brazo hemisférico de la AfL-cio. La ORIT fue creada después de la Segunda Guerra a iniciativa de la AFL para congregar en una sola organización a todos los sindicatos no-comunistas de América Latina, para de este modo contrarrestar la ya bien establecida organización comunista. Es cierto que la onrr ha dejado de ser la única organización no-comunista, ya que ésta debe encarar la competencia de un creciente movimiento obrero socialcristiano. Lo que distingue a la ORIT son los estrechos vinculos que unen a sus confederaciones del trabajo con los partidos socialdemócratas de América Latina: asi la Confederación del Trabajo Rerum Novarum se encuentra intimamente relacionada con el PLN de Costa Rica (doș miembros prominentes de ese Partido, el padre Benjamin Núñez y Luis. Alberto Monge, Sccretario General del PLN, han tenido importancia fundamental en el movimiento laboral oRI'T-Rerum Novarum); similarmente, la Confederación del Trabajo del Perú afrliada a la ORIT siempre ha tenido lazos estrechos con el APRA ${ }^{25}$ ia Confederación Nacional de Trabajadores Libres (CONATRAL) de la República Dominicana, en sus origenes, fue el brazo laboral del PRD; sin embargo, las tensiones que existen entre los dirigentes del PRD y la CONATRAL, dominada por la AFL-Cio, llevaron a que esta última se desafiliara del PRD y eventualmente a oponerse a la revolución dominicana, iniciada por el PRD, y a apoyar la invasión norteamericana ${ }^{26}$.

${ }^{24}$ Corominas, op. cit., pp. $123-4$.

25 Vor Kantor, The Ideology and Program of the Peruvian Aprista Movement (Washington: Saville Books, 1g66), pp. 89-go.

${ }^{26}$ Howard J. Wiarda, "The Development of the Labor Morement in the Dominican Republic", Inter-American Economic Affairs, Vol. 20, N" ; Susanne Bodenheimcr, "The Afl-clo in Latin America: The Case Study of the Dominican Republie", Viet-Report, septiembre-octubre 1967 . 
ESTUDIOS INTER NACIONALE S

La identificación estrecha de la or IT con los partidos socialdemócratas se ha ido debilitando en los pasados años en la medida en que muchos miembros de dichos partidos se han ido impacientando con el sindicalismo de meraś reivindicaciones económicas ("bread and butter") de la ORIT, así como por la abierta colaboración de ésta con los intereses comerciales, su débil apoyo y a veces abierta oposición a ciertas reformas sociales y económicas (incluso reformas minimas propiciadas por los socialdemócratas), por su papel subversivo en contra de regimenes populares tendientes a la izquierda, como ser el de Cheddi Jagan en la Guayana Británica, Joao Goulart en el Brasil, e incluso el régimen socialḋemócrata de Juan Bosch en la República Dominicana, y por su conperación abierta con dictadores o regimenes militares apoyados por el gobierno norteamericano, como, por ejemplo, Batista en Cuba y regimenes militares de derecha en Guatemala, Honduras y Brasil27? De ahi que Luis Alberto Monge, miembro del PLos, y quien fuera Secretario General de la ORIT, renunció a su cargo en $: 95^{8}$ en parte debido al apoyo que la ORIT prestaba a la Confederación del "Prabajo de Cuba, "que era conjuntamente con el Ejército cubano los dos pilares que sostenian la dictadura de Batista" ${ }^{28}$. El prestigio de la ORIT y sus confederaciones se vio menoscabado aún más cuando en 1967 se supo que un cierto número de ellas venía recibiendo fondos de la Cra, generalmente para actividades especificas vinculadas a la politica exterior de los Estados Unidosig. La experiencia obtenida por los socialdemócratas en la colaboración con la oRrr indica la contradicción inherente a la posición adoptada por los primeros: entre sus principios antimilitaristas, antidictatoriales y su mantención simultánea de lazos estrechos con organizaciones poderosas (o predominantes) de los Estados Unidos, las cuales apoyan o sirven los intereses norteamericanos, incluso cuando esta actitud significa el apoyo a sistemas diçtatoriales en América Latina.

27 Ver Sidney" Lens, "American Labor Abroad: Lovestone's Diplomacy", . Vation, julio 5. 1965; Dan Kurzman, "Lovestone's Cold War", Neu Republic, junio 25. 1966; Susannc Bodenheimer, "LI.S. Labor's Conservative Rol in Latin America", Progressive, nov. 1967; y numerosas declaracioncs de dichas actividades por personeros de la AFL-Cio y ORIT en sus propias publicacioncs.

${ }^{20}$ Robert Alexander, "Labor and Inter American Kelations", Annals, marzo, :961, p. +9 .

${ }^{29} \mathrm{Ver}$ George .Morris, ca and American Labor (New York: International Publishers, :(yj) 
El problema de los vinculos con los Estados Unidos se ha hecho presentc en otro de los principales órganos de la Internacional Socialdemócrata: la Escuela Interamericana de Educación Democrática (antes Instituto de Educación Politica). Esta cscuela fue fundada en 1959 por Figueres y sus colegas de Amćrica Latina con el propósito de educar jóvenes dirigentes en potencia miembros de los partidos socialdemócratas (incluidos ciertos grupos de exiliados cubanos y el Partido Demócrata de los Estados Unidos), en lo académico, idcológico $y$ en materia de práctica politica, asi como para contrarrestar las tácticas de penetración comunista ${ }^{29 "}$. Su objetivo era corregir lo que se pensaba como "preparación" insuficiente de la generación joven de socialdemócratas, quienes más tarde vendrian a ser los cuadros que habrian de llevar adelante la lucha contra las fuerzas totalitarias de derecha e izquicrda, la lucha por "la unidad continental dentro de un marco interamericanista y sin imperialismos", sca el de los Estados Unidos o cl de la Unión Soviética ${ }^{30}$. El Centro además publicaba la revista Combate, órgano principa! del pensamiento socialdemócrata de América Latina. En ella aparecian articulos firmados por muchos socialdemócratas ciel continente $y$ de sus colegas en el campo académico $y$ politico de los listados Unidos: Norman Thomas, Harry Kantor, Victor Alba, Robert Alcxander y Adolr Berie. Entre los instructores de la cscuela, con sede en La Catalina, cerca de San José, en Costa Rica, se encontraban numerosos personeros e intelectuales del PLN $y$ otros partidos socialdemócratas, otros "socialdemócratas" independientes, académicos y' politicos, incluidos algunos del Departámento de Ëstado de los Ëstados Unidos. El sccretariolesorero de la escuela cra Sacha Volman, rumano que había luchado contra los nazis $y$ los comunistas en su pais y quien después de haber salido de su pais en calidad de exiliado y' haberse dedicado a misteriosas aventuras alrededor del mundo, vino finaimente a trabajar con los socialdemócratas de América Latina a través del Instiluto Internacional de Investigación Laboral (nLR) dirigido por Norman Thomas. Fue este Instituto el que proveyó en un comienzo el financiamiento de la escuela de La Catalina. Hacia fincs de ig62 los fondos se agotaron y la cscuela fuc cerrada temporalmente, cmpero volvió a funcionar en 1964 . No fue hasta $: 967, \sin$

29aM. Rivera Matos, "Una escuela al servicio de la democrncin", (San José: Eatsad, 1g56).

${ }^{30}$ Rafael Pantoja, "El Institulo de Educación Politica”, Combnte, No :t, pp. 59-6r; ver tambièn Instituto de Educación Politicn (San Josí: 19601 ). 


$$
\text { C I O } \triangle A \text { : E } S
$$

embargo, que toda la historia de lá escucin se hizo pública: funcionaba con fondos suministrados por lá cıı, siendo la suma más o menos del orden de los US\$ 100.000 anuales ${ }^{31}$, canalizados a través de la fundación Kapian, una de las principales fundaciones utilizadas por la ca, y de alli a través del IILR de Norman Thomas y Volman. En :962, Volman comenzó a insistir que la escuela se ajustase a ciertas condiciones que êl llamaba "reformas" Cuando los otros directores de la escuela se negaron a ello, los fondos fucron suspendidos. Lo irónico dẹl caso es que la escuela comenzó a funcionar nucvamente, en $9_{964}$, otra vez con fondos de la cis a través de otro organismo canalizador: la Pan Amcricān Foundation de Florida. A pesar de que sabían cuál era la situación, los dircctores de La Catalina habian adoptado la actitud de no cuestionar la procedencia de los fondos, sicmpre y cuando fuesen entregados sin condiciones politicas ${ }^{33}$. Partiendo del supuesto que la escucla en el estricto sentido de la palabra no era una "herramiena" de la cia u otra organización de Washington, el hecho cs, sin embargo, que la existencia misma de la Escuela se debe a organizaciones norteamericanas para defender, lógicanıente, intereses norteamericanos. Incluso antes de que el financiamiento de la cis fucse hecho püblico, un personero del Departamento de Estado rcconoció que dicho Departamento "observaba con interés" $y$ "prestaba su apoyo moral" a los esfucrzos dẹsarrollados en la Escuela y a sus patrocinadores en los Estados Unidos ${ }^{34}$. Actilud razonable, ya que los graduados de la Escuela han ocupado importantes puesios en sus respectivos partidos (la mayoria de los cuales son pronorteamericanos); y dondequiera que estos partidos han tomado el gobicrno, como en Venezucla, Puerta, Rico y Costa Rica, los graduados de La Cata-

3. Minneapolis Sunday Tribune, marzo 24, 1963; fornularios para la exención de impucsios de! Internal Revenue Scrvice, presentados por al.R y por la Fundación haplan, respectivamente.

32Sacha Volman, discurso pronunciado en el Bronkings Institution, abril de 196.4, y

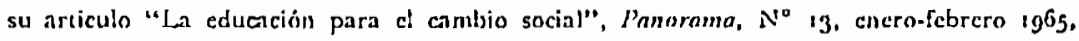
p. 37 .

33 Entrevistas; ver lambién cară de Figueres a Jaime .Maravites de La . Vación, la de marzo de 1967, Costa Rica.

34 Entrevista con V. P. Randolph, Costa Rican Desk Officer, Dept. of State, en el articulo de Robert Packenham, "Politicn! Development Doctrines in the American Forcig" Ait Progrnms", IIorld Politics, enero de sg66, pp. 220-1. 
Susanne Bodenheimer / La crisis del movimicnto socialdemócrata en América Latina lina han ocupado posiciones clave en el gobierno que abiertamente se ha adherido a la politica de los Estados Unidos, facilitando asi la penctración del capitalismo norteamericano en sus respectivos paises, así como han adoptado entusiastamente la politica de persecución y represión de los movimientos insurgentes nacionalcs.

Esta Escucla en La Catalina era sólo un eslabón en la cadena de instituciones establecidas por el IILR y' Volman que recibian fondos de la CIA. Otra empresa del ula fue el Centro de Estudios y Documentación Sociales, casa editorial en México a cuya cabeza se encontraba Victor Alba y que más tarde se convirtió en consejcro de! Institute for Free Labor Development dependiente de la AFL-cio, y que, entre otras cosas, publicaba la revista socialdemócrata Panorama. Finalmente, después de la experiencia obtenida en la Escuela de La Catalina, Volman y el IILR se dedicaron a la realización de mayores y mejores proyectos en la República Dominicana: el Centro Interamericano de Adiestramiento Polílico, dedicado a la educación de dirigentes campesinos, y a prestar todo el apoyo necesario a la candidatura, en 1962, de Juan Bosch; cuando Bosch ya era Presidente, cl Centro de Estudios Sociales (cides) funcionaba como el organismo central de planificación del corto régimen de Bosch (Volman se desempeñaba como consejero máximo y hombre de confianza de Bosch). Veamos lo que se dice al respecto:

"cides comenzó a desempeñar las funciones claves del gobierno dominicano: preparación de estimativos presupuestarios, proyectos de legislación, compilación de estadisticas, llevar a cabo encuestas y formulación de planes... cides se hallaba a ambiẻn planificando la forma en que habria de influir en el desarrollo politico de la nación a largo plazo... principalmente en lo que se refiere al programa de adiestramiento de personal a nivel medio por la combinación de la especialización técnica y el endoctrinamiento político... Finalmente cides intentó establecer un programa de educación masiva para de esta forma crear el apojo popular para è desarrollo e identificar a los dirigentes en potencia de la comunidad"ss. Sumados a los fondos proporcionados por la cia, cides recibía ayuda financiera del Fondo Especial de contingencia del Presidente de los Estados Unidos, siendo el consejero clave de la organización, aparte de Volman, el funcio-

${ }^{35}$ Alsraham F. Lowenthal, "Foreign Aid as a Political Instrument: the Case of the Dominican Republic", Public Policy, Vol. xu, p. 157. 
ESTUDIOS I T TER NACIONALE S

nario de AD Alvin Mayne ${ }^{36}$. Lo que hacia que esta organización fucse ideal para el encauzamiento de la politica de desarrollo de la República Dominicana -a pesar de que se reconocia que violaba los "conceptos tradicionales de soberanía"-, cra el manto que la cubria: el IILR, organización no-gubernamentai, lo cual "permitía el libre desenvolvimiento de la actividad norteamericana, al tiempo que protegía a ambos gobiernos contra acusaciones de intervención"37.

Otro organismo del moviniento socialdemócrata internacional: la Asociación Inleramericana para la Democracia y la Liberlad, que tuvo su origen en el Congreso de Partidos Demócratas y' Populares de América de $1940^{38}$, y que en realidad no vino a fundarse hasta :950, $y$ cuyos fines eran el estudio y la acción contra el resurgimicnto de las idcas neofascistas y comunistas en el hemisferio. Bl boletín de noticias de la Asociación Hemisférica servia como vehículo de difusión de la filosofia socialdemócrata y atacaba tanto a las dictaduras militares de derecha como a las activiáades de la "extrema" izquierda. Entre los personeros y micmbros activos de la Asociación se encontraban prominentes dirigentes latinoamericanos: Figueres, Belancourt y' Lleras Restrepo de Colombia, y entre los norteamericanos: Seralino Romualdi, William Doherty y Andrew MicClellan (tocios estos asociados con la AFl-cio y/o la oRIT), Robert Alexander, John Plank, Russell Fitzgibbon y Frank Tannenbaum (investigadores de la socialdemocracia latinoamericana), el senador Edward Kennedy, Arturo Morales Carrión, ex personcro del Departamento de Estado (con anterioridad ayudante de Nuñoz Mlarin de Puerto Rico), y' hasta su reciente deceso el ubicuo Norman Thomas. La primera conferencia de la Asociación, llevada a cabo en 1950, cmitió una resolución en la que se instaba la descontinuación de la ayuda $y$ el no reconocimiento diplomático de los regimenes dictatoriales, $y$, sin cmbargo, fuc rechazado un proyecto de resolución de la delegación mexicana en la que se criticaba la acción de la iglesia católica y de los manopolios norteamericanos ${ }^{39}$. La segunda conferencia fue en abril de ig6o en la que se condenó las dictaduras de la República Dominicana, Haiti, Nicaragua y Paraguay, $y, \sin e m b a r g o$, no se

${ }^{30}$ A. F. Lowenthal, op. cil., p. 155.

37. A. F. Lowentha!, op. cit., p. 155.

38Villanucva, op. cit., Combalc, $N^{\circ}$ I8, p. 14; Kantor, "La colaboración...", p. 6 g.

3911 re, mayo de 1950. 
Suranne Bodenheimer / La crisis del movimiento socialdemócrata en América Latina aceptó la presión ejercida por la delegación norteamericana y de los primeros grupos de exiliados cubanos en el sentido de censurar al régimen de Castro, el cual aún no se habia "convertido en comunista" que no se habia llegado a emitir una resolución de condena del régimen de Castro debido a que la conferencia de 1960 habia sido infiltrada por comunistas invitados por uno de los partidos anfitriones de Venezuela ${ }^{41}$ Esta experiencia pareció haber convencido a algunos de los socialdemócratas hacia la necesidad de una organización más pequeña y cerrada a la vez; de ahí que cinco de los partidos que formaban el meollo de la organización celebraron la Conferencia de Partidos Populares en 1960, la cual instó a un "boycot de las tiranias" y dio a publicidad una velada declaración de advertencia a Castro en el sentido de no convertirse en antidemócrata o factor "divisor" en el seno de las fuerzas populares del continen$t^{42}$. De este grupo, Figueres y Haya de la Torre se adjudicaron la tarea de movilizar el apoyo de los partidos sucialdcmócratas a la "nueva actitud de los Estados Unidos" bajo el gobierno de Kennedy y la Alianza para el Progreso ${ }^{43}$.

De este somero repaso de las organizaciones y actividades de los socialdemócratas latinoamericanos podemos sacar ciertas conclusiones: Primera: todo indica que este fenómeno es algo más que una serie de grupos independientes internacionales; es un complejo cultural-politico, un movimiento internacional, una red de individuos y organizaciones premeditadamente dedicados a una misión interamericana y decididos a librar batalla en favor de la democracia social en todos los frentes: militar, laboral, cultural y politico. De acuerdo a ello no es puies sorprendente que muchos individuos tanto latinoamericanos como norteamericanos se hayan visto envueltos simultáneamente en estas organizaciones, para asi unirlas $y$ formar un movimiento cohesivo.

Segunda: el objetivo supremo de la internacional socialdemócrata ha cambiado a través de los años como respuesta a las condiciones cambianles en América Latina. A pesar de que siempre estuvo presente la preocu-

40 liar, abril de 1960.

${ }^{41}$ Kantor, "La colaboración...", pp. 73-4.

42 "Declaración de Lima", en Lalinoamérica más allá de sus fronteras, pp. 109-I 19.

${ }^{43}$ Kantor, "La colaboración. . ", pp. 7.1-5. 
pación por la expansión de la revolución comunista en Ámérica Latina ${ }^{44}$, el énfasis ha sido puesto, durante las décadas del 40 y el 50 , en la lucha contra las dictaduras tanto militares como civiles del ala derecha; después de que la revolución cubana se convirtió en revolución comunista, estos grupos han redoblado el esfuerzo de iucha contra el comunismo y todo movimiento revolucionario.

Tercera: es necesario hacer algunas consideraciones acerca de los fuertes lazos que unen a estos grupos con los circulos liberales de los Estados Unidos, desde el ala de Kennedy del Partido Demócrata (a pesar de que muchos de los dirigentes latinoamericanos tienen relaciones estrechas con Humphrey) hasta el sector independiente socialdemócrata de Norman Thomas. A pesar de las diferencias que existen entre ellos, estos socialdemócratas en ambos lados del continente comparten una firme decisión de adherencia a su ideologia y una obstinada oposición al comunismo revolucionario. Quizás es este último aspecto el que ha hecho que estos grupos merezcan especial atención en lo que al apoyo financiero se refiere de parte de la cis. Para los responsables de la politica exterior norteamericana que son suficientemente "perspicaces" para comprender que los movimientos revolucionarios son mejor combatidos por medio de una estructura politico-reformista en lugar de la fuerza militar, el movimiento socialdemócrata es indudablemente un instrumento efectivo en la pacificación de América Latina.

Es precisamente el valor en si que tienen estos grupos para la defensa de ciertos intereses tanto oficiales como privados de los Estados Unidos lo que implica el fracaso de la socialdemocracia como vehiculo de cambios revolucionarios urgentes en la América Latina de hoy. La sociaidemocracia ha dejado de tener la iniciativa y se ha visto relegada a un restringido campo de acción. Aquellos socialdemócratas que no se han decidido a virar hacia la izquierda, se han visto obligados por la lógica de los sucesos y por sus propios intereses de clase, en situaciones dadas, a formar parte de la derecha.

El significado concreto de esta creciente polarización se manifestó dramáticamente en $9^{6} 6_{5}$ durante la crisis dominicana y las reacciones que clla ocasionó. Habiendo sido lanzados por los hechos a formar una alianza con la izquierda revolucionaria, los socialdemócratas dominicanos del PRD SE

\footnotetext{
${ }^{44}$ Kantor, p. 73 .
} 
Susanne Bodenheimer / La crisis de! movimiento socialdemócrata en Amćrica Latina vieron abandonados por sus ex aliados de todo el continente. El gobierno PLi' de Francisco Orlich de Costa Rica envió un destacamento policiaco como parte de la "Fuerza Interamericana de Paz" en apoyo a la invasión norteamericana. John Bartlew Martin, otrora embajador norteamericano del gobierno Kennedy en la República Dominicana y persona muy allegada al círculo Kennedy, hacia el cual Bosch tenia gran respeto ${ }^{45}$, visitó, a instancias del Presidente Johnson, a Bosch para explicarle que la revolución dominicana estaba a punto de caer en manos comunistas y que por consiguiente tenía que ser sofocada por medio de una intervención norteamericana; al mismo tiempo Martin estaba envuelto en negociaciones con los generales antirrevolucionarios dominicanos para la formación de una junta de gobierno provisional ${ }^{46}$. Es más, los socialdemócratas norteamericanos que en un principio protestaron contra la intervención norteamericana eventualmente llegaron a jugar un papel en la confirmación del fracaso del movimiento constitucionalista pro-Bosch: respecto de la elección de 1966 - mientras el pais se encontraba aún ocupado por 8.000 soldados "guardianes de la paz" y en medio de una atmósfera de terror- ${ }^{47}$, una comisión de observadores norteamericanos con Norman Thomas a la cabeza $y$ que incluia otros prominentes socialdemócratas declaró que "de acuerdo a la mejor impresión que tenemos, la votación ha sido justa y sin intimidación" 48 ; este informe, que en efecto y en esencia hacia legitima la derrota de Bosch, está en abierta contradicción con el informe presentado por la comisión independiente de observadores porto:rriqueños, quienes, a la inversa de los miembros de la comisión norteamericana, hablaban español, y que observó las elecciones en las provincias rurales del país muy afectas al fraude electoral ${ }^{49}$. Al contar con amigos

${ }^{45} \mathrm{Juan}$ Bosch, Crisis de la democracia de América en la República Dominicana (México: Centrn de Estudios y Documentación Suciales, $: 96.4$, p. 157.

46 "An Encounter", relatos de Juan Bosch y John Bartlow Martin en San Juan Review, agosto de 1965, pp. 8-12.

47"Were de Dominican Elections Honest?", entrevistas con observadores portorriqueños, San Juan Review, julio de : 966 , pp. :2-16; Ruth Shereff, "The Committees for Free Elections in the Dominican Republic", Liberation, noviembre de 1966; Susanne Budenheimer, "The Hidden Invaders: Our Civilian Takcover in the Dominican Republic", Liberation, Tebrero de : 967 .

48 Selden Rodman, "W"hy Balaguer Won", . Vew Republic, 18 de junio de 1966.

49 "Were the Dominican Elections Honest?". 
"demócratas" como éstos, no es pues sorprendente que Bosch haya hecho llamados en el sentido de instaurar "dictaduras populares" en América Latina, ya que la llamada "democracia" está "muerta e incinerada" y "no puede resolver el cúmulo de problemas que los diferentes paises afrontan"so.

En otros paises de América Latina la socialdemocracia ha sido inmovilizada o ha virado hacia la derecha. El PLN de Costa Rica, el cual ha estado en el poder tres veces a partir de la revolución de 1948 , no ha podido apartarse de los ideales y medidas politicas que habia adoptado como suyos durante la década del 40; en consecuencia, en lugar de adaptarse a la creciente presión para la transformación social y económica, los gobiernos dei PLN se han ido convirtiendo progresivamente en gobiernos conservadores. Excepción hecha de la nacionalización del sịstema bancario llevada a efecto por la junta de Figueres en 1948 , ios gobiernos PLi no han iniciado reforma estructural alguna que frenase el poder de los intereses económicos tanto extranjeros como nacionales. A pesar de que una ley de reforma agraria, sancionada en ig61, le conferia al gobierno el poder legal de expropiar todas las tierras incultas, el régimen PLN de Francisco Orlich de 1962-1966 encauzó todos sus esfuerzos hảcia la "colonización" de tierras pertenecientes al Estado en lugares alejados y de poca poblaciôn. A pesar de los enunciados elocuentes de los derechos del trabajador, los gobiernos PLN consistentemente han inclinado la cabeza ante la presión antisindicalista de las compañias privadas, especialmente ante la United Fruit que controla vastas zonas de plantaciones de plátano donde los comunistas ejercian influencia considerable en los sindicatos ${ }^{52}$. En lugar de restringir las franquicias y privilegios de que goza el capital extranjero, los gobiernos PLN han redoblado sus esfuerzos para atraer más inversión extranjera. Ilan concedido a un gran número de firmas norteamericanas (fuera de la United Fruit, la Pan American ha obtenido una participación por medio de la cual controla la Línea Aérea Costarricense - LACSA52 y la Alied Chemical $\left.{ }^{53}\right)$, derechos de monopolio para la operación en Costa

50:Juan Bosch, citado en el Miami Herald, $:^{\circ}$ de octubre de 1967.

$51^{\prime}$ Ver por ejemplo HAR, agosto, scptiembre y octubre de 1955; abril de 1959; julio de 1963.

5 ₹ HAR, marzo y mayo de 1958 .

53 Has, junio de 1963 . 
Susanne Bodenheimer / La crisis del movimicnto sncialdemócratin cn Amćrica Latina Rica. Los programas de desarrollo bajo los gobiernos PLN han sido financiados no a través de la reforma tributaria sino a través de los empréstitos cxtranjeros, los cuales incluyen préstamos a corto plazo en extremo desventajosos que se obtuvieron durante el.gobierno de Orlich ${ }^{154}$. Las medidas tendientes al bienestár del pueblo no han sido extendidas a la mayoria de la población: hacia I955, por cjemplo, el seguro médico a través del seguro social sólo cubría un 26,8 por ciento de la población'ss. Finalmente, a pesar del declarado antimilitarismo de los gobiernos PLN tanto a nivel nacional como internacional, éstos han empleado fuerzas paramilitares en la arena internacional, siendo c! más notable de los casos la "donación" de Orlich de fuerzas policiacas a la Fuerza Interamericana de Paz, de inspiración norteamericana, que invadió la República Dominicana en :965, y han participado en encuentros del Consejo de Defensa Centroamericana, CONDEC $\curlywedge$, dejando al gobierno conservador $y$ anti-PLN de Trejos la empresa de retirar a Costa Rica de CONDECA ${ }^{56}$. En fin, han permitido que la Misión Militar Norteamericana permanezca en el pais siendo asi que Costa Rica no tiene ejército oficial. Vemos pucs que en muchos respectos las medidas licvadas a efecto por los gobiernos PLN están en abierta contradicción con los principios ideológicos del partido ${ }^{56 \cdot a}$.

Un vistazo a la labor desenvuelta por Acción Democrática (AD) en Venezucla, en el poder desde $195^{8}$ hasta su derrota cn 1968 , tampoco nos da rcsultados halagücños. La importante y crucial industria dẹ petróleo, la cual representa el 68 por ciento de la inversión total extranjera, el 93 por ciento del ingreso por concepto de exportación, el 26 por ciento del producto nacional bruto y el 63 por ciento del ingreso a las arcas de la nación, y que sin embargo sólo emplen el 1,1 por ciento de la fucrza laboral activa, ha seguido perteneciendo, durante dos gobiernos $A D$, a los consorcios norteamericanos, principalmente a la Standard Oil of New Jersey. La empre-

34 Donn Scot: Smith, "The Partico Libcración Nacional of Costa Kica: A critical Study" (10is no publicada, presentada al Wondrow Wilson School, Princcton University, 1966), p.9.

55 Inter-American Development Bank, Socio-Economic Progress in Latin America, val Informe anual, agok (Washinglon: uIs), 1969), p. I33; ver lambién Chartes Auderson, Politics and Economic Change in Latin imerica (Princeron: Van Nostrand, 1967), p. 284 ).

so La Vación (San José), 6 de septiembre de 1967.

so "Para más detalles sobre el PLx ver mi articulo: "The Socia! Democratic Ifeology in Latin America: The case of Costa Ricn's Partido de Lilseracion Nacional". 
E S T U DIOS INTER NA C I O N A L E

sa petrolera controlada por el gobierno sólo produce el I por ciento de la producción nacional. Dos tercios de la refinación del petróleo, empresa altamente lucrativa, se llevan a cabo en el extranjero5?. Los gobicrnos AD han concedido derechos de control a corporaciones norteamericanas en muchas otras c importantes industrias: el acero, la industria petroquimica, la de fertilizantes, $y$ han pcrmitido que el capital extranjero penetre en las esferas mercantiles, del comercio y en los sectores de servicios de la economia ${ }^{58}$. La ley de reforma agraria de $A D$ ha sido pucsta en la práctica en forma lenta y clla no ha cambiado básicamente la cstructura de clases $y^{\prime}$ las relaciones sociales en el agro. $\mathrm{Ha}^{2}$ distribuido tierras a sólo 160.000

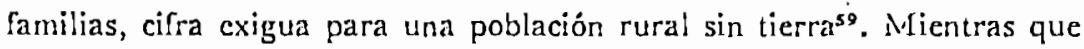
el ingreso per cápita de la mación como un todo era de US\$840.00, en 1965 , el del sector agricola era sólo de US\$200.0060. Otras reformas importantisimas, como sç la reforma de la tributación, no han sido llevadas a efecto. Mientras tanto, bajo la fachada de una "democracia", los gobicrnos a de Betancourt $y$ Leoni han hecho uso de una despiadada táctica policiaca secreta para la represión de los movimientos revolucionario y estudiantil: en diciembre de 1966, la tradicional autonomia universitaria fue violada cuando el gobierno envió tropas para la ocupación del recinto universitario; en $19^{67}$, año batutizado por el Ministro del interior como el "año de la pacilicación" "as garantias constitucionales fueron suspendidas en repetidas ocasiones, Betancourt las suspendió tres veces, una de ellas por espacio de dos años ${ }^{62}$. $Y$ en el campo internacional, ambos gobiernos tomaron la delantera en la acción desplegada por la OE৯ contra Cuba. Mientras los dos gobiernos $A D$ Luvieron un relativo éxito en llevar a cabo el objetivo formalista "democrático" de celebrar eleccioncs constitucionales para la sucesión presidencial, por otro lado no han vacilado en abrogar la substancia, o por lo menos ciertas formas, de la democracia. Sin embar-

${ }^{57}$ Cifras tomadas det liorth American Congress on Latin America (NincL) . Tewsletter, abril-mayo de igrigi inmbicn de The Economist for Lalin America, 11 de diciembre de 1658, p. 7 .

58 The Economist for Lakin America, 27 de noviembre de I968, p. 40; y Drew Penrson ell cl Il'ashington Post, 17 de encro de 1967.

52 The Economist for latin Americn. 27 de noviembre de 1958. p. 39.

60 The Economisi for Latin America, p. fo.

61 Diario de las siméricas, 27 de diciembre de 1967.

62 ll'ashington Post, 5 de marzo de rof67; y . Niami Merold, fi de agosto de ig67. 
Susanne Bodenheimer / La crisjs del movimiento sncialdemócrata en América Latina go, el precio pagado ha sido elevado: independientemente de la derrota electoral de diciembre de $\mathrm{r} 968, \wedge \mathrm{D}$ ha sufrido numerosas escisiones. $y$ abandono de segmentos izquierdistás que no estaban conformes con seguir tolerando la politica represiva y "entreguista" del partido.

En Guatemala, a partir de 1966 , año en que el Partido Radical tomó el gobierno -el cual fue elegido sobre las bases de una promesa de seguir llevando adelante la interrumpida revolución de Arévalo y Arbenz-, éste ha ido cediendo la autoridad inherente al gobierno a las fuerzas armadas $y$ ha maldirigido sus recursos y energias hacia la "defensa" contra la "amenaza" que significa la revolución interna, en lugar de aplicarlos hacia la reforma. Los intentos a medias del PR para iniciar la reforma tanto agraria como tributaria han sido fácilmente anulados por los intereses creados de los terratenientes, comerciantes e industriales. La penetración del capital norteamericano - e influencia militar - ha sido permitida por el PR en forma jamás conocida antes ${ }^{63}$. Aquellos socialdemócratas en Guatemala que no se han hallado directamente comprometidos con el gobierno han sido virtualmente paralizados e incapacitados para actuar en forma alguna contra el estado de sitio oficial que reina en el pais y contra el terrorismo de los grupos vigilantes de extrema derecha. Vemos pues que la actuación de estos gobiernos socialdemócratas - asi como de otros: el PPD en Puerto Rico y el Partido Radical en Chile- revela la flagrante disparidad que existe entre la ideologia o retórica y la práctica. Incluso en el caso de que aún no han llegado al poder, los movimientos socialdemócratas no han llegado a superar esta discrepancia. En el Perú cl APRA, con Haya de la Torre a la cabeza, ha ido convergiendo firme y gradualmente hacia la derecha, giro que culminó con la alianza parlamentaria del APR $\lambda$ con las fuerzas del ex dictador General Odria, durante el gobierno de Belaúnde, $1963-1968$. Tampoco [ue la primera vez que e] APRA demostró su "flexibilidad": en 1956 firmó un pacto ciectoral con las fuerzas conservadoras de Prado. El papel del APRA bajo el gobierno de Belaúnde fue de tipo parlamentario obstruccionista $y$ conservador. La alianza APRA-Odría en el Legislativo previno la aprobación de un proyecto de ley de Belaúnde por espacio de casi un año que comprendia ciertas tímidas medidas de reforma tributaria para el financiamiento de progra-

63 Ver Alfonso Bauer Paiz, "The "Third Government of the Revolution' and Imperialism", a ser publicado en Leviathan, octubre de 1969 (?). 
mas gubernamentales con el pretexto de que los gastos deberian ser reducidos en lugar de elevar los impuestos. Es más, no fue el APRA ni el gobierno civil de Belaúnde pero si el gobierno militar del General Velasco el que ha iniciado el primer intento serio de reforma agraria, que ha nacionalizado la explotación. petrolera de la International Petroleum Co., subsidiaria de la Standard Oil, y ha tomado en sus manos otras reformas estructurales. Cuando la junta militar nacionalizó las propiedades de la referida compañia petrolera, a fines de $\mathrm{g} 68$, el APRA fue el único partido politico en el Perú que se abstuvo de hacer comentario alguno sobre la acción tomada. Se refirió a la junta como peligrosa ya que "substituiria un imperialismo por otro" y con ello aludía al imperialismo de los paises socialistas ${ }^{64}$. Cuando la Junta promulgó la amplia ley de reforma agraria, en junio de 1969 , Haya de la Torre dijo que "dicha ley siempre habia sido el ideal del APRA a partir de $193^{1205}$, a pesar de que el programa pertinente del APRA para las elecciones de 1962 fue en extremo vago, y en 1964 habia tratado de debilitar el proyecto de ley agraria presentado por Belaúnde al Congreso.

Los ejemplos reseñadós demuestran la existencia de ciertas contradicciones en la posición socialdemócrata. Una de ellas es lo ilusorio que resulta ser la posición liberal anticomunista sobre bases permanentes: dadas ciertas situaciones concretas en las que actúa un sinnúmero de fuerzas tanto extranjeras como nacionales en la América Latina de hoy, tarde o temprano habrá de llegar el momento ineludible de elección, es decir en la práctica y no sólo teóricamente, entre un reformismo progresista $y$ un anticomunismo de principios y reacio al compromiso; $y$ en muchos casos ya dados los socialdemócratas se han aliado con las fuerzas anticomunistas. El celo anticomunista que profesan y el empleo que han hecho del poder estatal, tanto policiaco como militar, para aplastar los movimientos revolucionarios en Guatemala, Venezuela y otros paises revelan la debilidad de su credo antimilitarista, asi como la retórica que emplean al referirse a la transformación socioeconómica de la América Latina. Pero hay algo, a mi juicio, que es mucho más fundamental: hoy' por hoy el objetivo de la socialdemocracia es la de elevar la posición de las clases bajas sin desafiar abiertamente a los poderosos intereses de las

64. Vew Y'ork Times, 23 de febrero de :969; Oiga, 28 de febrero de I96g.

65. Lalin America, (new'sletter) 4 de julio de 1969 . 
Susanne Bodenheimer / La crisis del'movimiento socialdemócrata en América Latina clases altas; y es aqui donde la experiencia nos demuestra que en la práctica han defraudado las promesas retóricas hechas a las masas y por ende reforzado la posición de las élites terrateniente, comercial $c$ industrial. En este sentido la social democracia ha revelado en la práctica lo que ideológicamente trata de obscurecer: que por debajo de la retórica universalista y $\sin$ clases, el movimiento sigue siendo la creación e instrumento de la clase media cuyos intereses están cada vez más identificándose con los intereses de la clase alta a expensas de sus ex aliados: las clases bajas. Por tanto, la base de clase de la socialdemocracia en América Latina la imposibilita en la realización de sus principios declarados. Son pues el rechazo obstinado y la simultánea incapacidad de superar esta base clasista los factores determinantes de las limitaciones histórico-sociales de la socialdemocracia en América Latina y por ende de la crisis de este movimiento como fuerza progresista del futuro. 